\title{
DÜBLIN
}

Technological University Dublin

ARROW@TU Dublin

Conference Papers

Biomedical Devices and Assistive Technology

Research Group

2011-09-05

\section{Soft Tissue Cutting with Ultrasonic Mechanical Waveguides}

\author{
Mark Wylie \\ Technological University Dublin, mark.wylie@tudublin.ie \\ Garrett McGuinness \\ Dublin City University \\ Graham Gavin \\ Technological University Dublin, graham.gavin@tudublin.ie
}

Follow this and additional works at: https://arrow.tudublin.ie/biodevcon

Part of the Biomedical Engineering and Bioengineering Commons

\section{Recommended Citation}

Wylie, M., McGuinness, G. \& Gavin, G. (2011) Soft Tissue Cutting with Ultrasonic Mechanical Waveguides. International Congress on Ultrasonics 2011, Gdansk, 5-8, September. Book of Abstracts : ISBN 978-83-7531-215-7 Proceedings: TBA

This Conference Paper is brought to you for free and open access by the Biomedical Devices and Assistive Technology Research Group at ARROW@TU Dublin. It has been accepted for inclusion in Conference Papers by an authorized administrator of ARROW@TU Dublin. For more information, please contact arrow.admin@tudublin.ie, aisling.coyne@tudublin.ie, gerard.connolly@tudublin.ie.

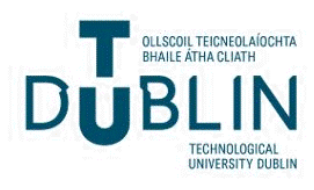




\title{
Soft Tissue Cutting with Ultrasonic Mechanical Waveguides
}

\author{
Mark. P. Wylie ${ }^{\mathrm{a}}$, Garrett McGuinness ${ }^{\mathrm{b}}$ and Graham. P. Gavin ${ }^{\mathrm{a}}$ \\ ${ }^{a}$ Dublin Institute of Technology, Design and Manufacturing Engineering Dept', Bolton Street., Dublin 1, Ireland \\ ${ }^{b}$ Dublin City University, Mechanical and Manufacturing Engineering Dept', Glasnevin, Dublin 9, Ireland
}

\begin{abstract}
The use of ultrasonic vibrations transmitted via small diameter wire waveguides represents a technology that has potential for minimally invasive procedures in surgery. This form of energy delivery results in distal tip mechanical vibrations with amplitudes of vibration of up to $50 \mu \mathrm{m}$ and at frequencies between $20-50 \mathrm{kHz}$ commonly reported. This energy can then be used by micro-cutting surgical tools and end effectors for a range of applications such as bone cutting, cement removal in joint revision surgery and soft tissue cutting. One particular application which has gained regulatory approval in recent years is in the area of cardiovascular surgery in the removal of calcified atherosclerotic plaques and chronic total occlusions. This paper builds on previous work that was focused on the ultrasonic perforation of soft vascular tissue using ultrasonically activated mechanical waveguides and the applied force required to initiate failure in soft tissue when compared with non-ultrasonic waveguides. An ultrasonic device and experimental rig was developed that can deliver ultrasonic vibrations to the distal tip of $1.0 \mathrm{~mm}$ diameter nickel-titanium waveguides. The operation of the ultrasonic device has been characterized at $22.5 \mathrm{kHz}$ with achievable amplitudes of vibration in the range of $16-$ $40 \mu \mathrm{m}$. The experimental rig allows the ultrasonically activated waveguide to be advanced through a tissue sample over a range of feedrates and the waveguide-tissue interaction force can be measured during perforation into the tissue. Preliminary studies into the effects of feedrate on porcine aortic arterial tissue perforation forces are presented as part of this work. A range of amplitudes of vibration at the wire waveguide distal tip were examined. The resulting temperature increase when perforating artery wall when using the energized wire waveguides is also examined. Results show a clear multistage failure of the tissue. The first stage involves a rise in force up to some critical force and tissue displacement whereby the cut is initiated. The results show that with increasing ultrasonic amplitude of vibration the perforation force decreases considerably. The current results show that for the range of feedrates investigated $19-95 \mathrm{~mm} / \mathrm{min}$ at an amplitude of vibration of $34.3 \mu \mathrm{m}$ there was no significant effect on the perforation initiation force. The $\Delta \mathrm{T}$ in the tissue $3.0 \mathrm{~mm}$ from the point of entry is also presented for a range of amplitudes of vibration.
\end{abstract}

Keywords: Therapeutic ultrasound, wire waveguide, tissue dissection

PACS: 43.35.Wa, 43.80.Qf, 87.50.yt, 87.63.D

\section{INTRODUCTION}

Complications arising with the treatment of totally occluded atherosclerotic arteries by standard dilation procedures such as Percutaneous Transluminal Interventions (PTI), typically an angioplasty balloon and stent, has prompted research into alternative treatments. These chronic total occlusions (CTOs) are generally associated with tough fibrous plaque caps are difficult to engage and transverse with the traditional guidewires, and may require a more invasive graft surgery. Recently, a number of techniques have been devised to facilitate the crossing of the traditional guidewire by creating a lumen or viable path through the fibrous cap and lesion. One such technique proposes that the lesion is disrupted with an ultrasonically vibrating wire waveguide. Recently, the first ultrasonic device was approved (FDA and EU, 2007 and 2005 respectively) for the treatment of CTOs using ultrasonic energy delivered via a wire waveguide[1].

Preliminary bench-top experiments, in the early 1990's, using ultrasonic prototypes applied to thrombolysis and angioplasty discovered that a number of ablation mechanisms were responsible for the tissue disruption. The generation of heat when using ultrasonic angioplasty devices was also commonly reported $[2,3]$.

It is thought that hard diseased tissue and thrombus dissolution is thought to be disrupted by a number of mechanisms; primarily direct mechanical ablation and cavitation with many investigators suggested that the presence of cavitation was necessary for plaque ablation and thrombus disruption. Acoustic streaming and pressure wave components may also contribute to the hard tissue disruption [4]. The ablation mechanisms for soft tissue disruption, however, are less well known. The aim of this study is to examine the effects of feedrate on the perforation initiation force of soft healthy arterial tissue. Temperature changes in the tissue near the waveguide distal tip are also presented. 


\section{METHODOLOGY}

To examine the perforation forces and thermal elevation using an ultrasonically vibrating wire waveguide, an apparatus similar to that detailed in the literature was developed. This operated at $22.5 \mathrm{kHz}$ delivering amplitudes of vibration between $15-40 \mu \mathrm{m}$ to a $1.0 \mathrm{~mm}$ flat waveguide distal tip.

The ultrasonic apparatus was used for testing within a bench-top test rig. The main design features include, accommodation of the ultrasonic apparatus to a vertical motorised lead screw assembly which can advance the apparatus over a range of feedrates $(19-95 \mathrm{~mm} / \mathrm{min})$ and a cantilever beam tissue sample holder, as shown in Figure 1. The experimental set-up is described in greater detail elsewhere [5]. The cantilever beam assembly included a half-bridge temperature strain gauge arrangement and was calibrated to provide force feedback. This allowed for perforation of the tissue through a $3.0 \mathrm{~mm}$ pilot hole. The cantilever beam tissue holder also allowed for the placement of a thermocouple close to the point of entry of the wire waveguide. It could be located $3.0 \mathrm{~mm}$ (centre to centre) from the pilot hole for the wire waveguide. A rapid response pot sealed $1.0 \mathrm{~mm}$ diameter, custom made $\mathrm{K}$ Type mineral insulated thermocouple was used. This assembly, including sensors were designed to be held in a liquid thermostatic tank at $37^{0} \pm 0.2 \mathrm{C}$.

For all tests healthy porcine vascular tissue was used within 24 hours after death and stored (mixed) in a 0.9 $\%$ refrigerated saline solution. Approximately $250 \mathrm{~mm}$ length of the descending thoracic aorta was extracted. Connective tissue was removed and $10 \times 20 \mathrm{~mm}$ radial sections were cut from the tissue sample. Sample tissue thickness ranged between $2.5-3.5 \mathrm{~mm}$ approximately. For each test, the aortas sections were then spread flat and clamped in the cantilever beam tissue holder (inner endothelium uppermost to represent an inside-out wire perforation) and submerged in the thermostatic tank.

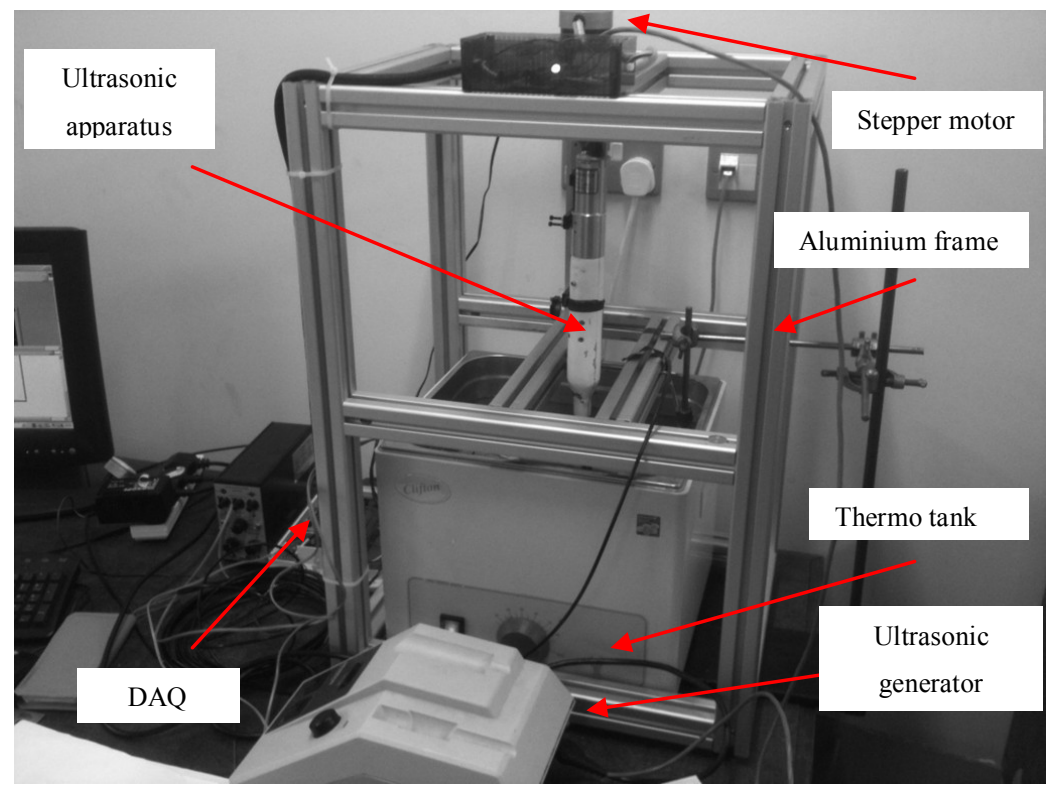

FIGURE 1. Experimental test rig with ultrasonic apparatus attached. 


\section{RESULTS AND DISCUSSION}

\section{Perforation force}

FIGURE 2 shows an example of the force profile during tissue perforation both, with energized $(16 \mu \mathrm{m}, 25$ $\mu \mathrm{m}$ and $40 \mu \mathrm{m}$ ) and a non-energized waveguide. The forces required to perforate the tissue are seen to reduce with increasing amplitudes of vibration. By using ultrasonically activated wire waveguides, even at the lowest amplitudes of vibration tested here $(16 \mu \mathrm{m})$, a $37 \%$ reduction in the force required to perforate the artery wall is achieved. Further reduction in perforation forces are measured with 25 and $40 \mu \mathrm{m}$, however the benefits or increasing the amplitudes of vibration to these levels are not substantial in regards to perforation force reduction.

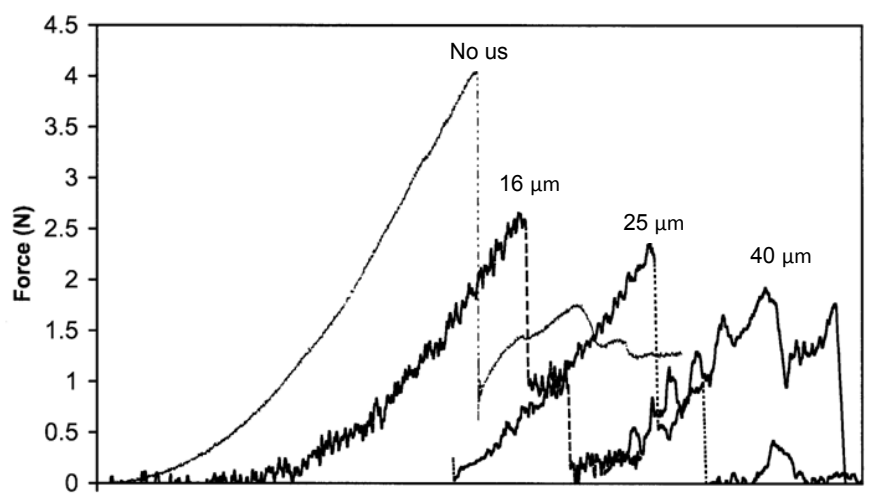

FIGURE 2. Perforation force profiles with no ultrasound applied (No us) and for ultrasonic wire waveguide distal tip displacement of 16,25 and $40 \mu \mathrm{m}$.

\section{Feedrate}

The perforation initiation force was examined for the feedrate tests; this is the force required to initially perforate the tissue (i.e. first peak in force-profile data). FIGURE 3 shows perforation initiation force for a range of feedrates $(19-95 \mathrm{~mm} / \mathrm{min}$ ) for an energized wire waveguide with amplitude of vibration of $34.3 \mu \mathrm{m}$. For these settings there is no clear effect of feedrate on perforation initiation force. Mean perforation initiation force values are lowest at $38 \mathrm{~mm} / \mathrm{min}$ and may suggest preferable feedrates for cutting.

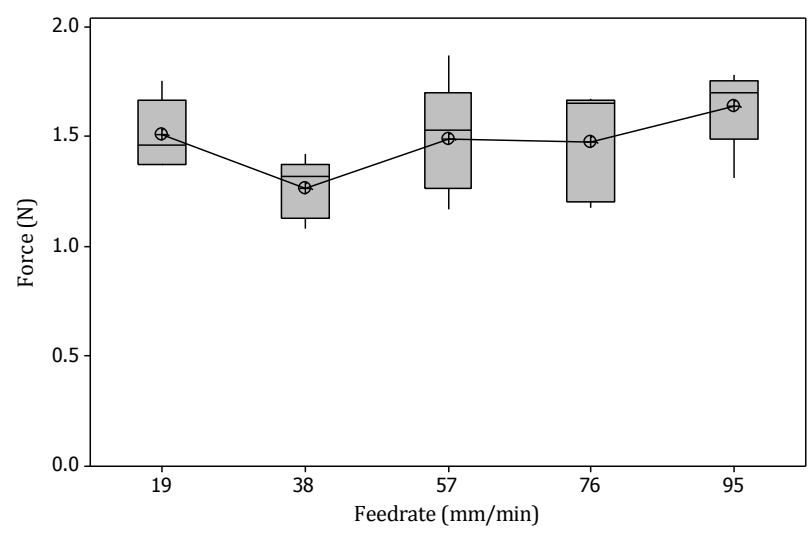

FIGURE 3. Perforation initiation force for a range of feedrates $(19-95 \mathrm{~mm} / \mathrm{min})$ for an energized wire waveguide with amplitude of vibration of $34.3 \mu \mathrm{m}$. 


\section{Temperature rise}

The temperature rise $(\Delta \mathrm{T})$ from the wire waveguide perforating the arterial tissue with amplitudes of vibration from $22.5-34.3 \mu \mathrm{m}$ (feedrate $=38 \mathrm{~mm} / \mathrm{min}$ ) was measured and shown in FIGURE 4 below. Where $\mathrm{T}_{2}$ is the final maximum temperature after perforation and $T_{1}$ is the initial ambient temperature of the tissue in the thermostatic tank $\left(37^{0} \mathrm{C} \pm 0.2\right)$. Increasing amplitude of vibration (acoustic intensity) is associated with an increase in $\Delta \mathrm{T}$. The thermal profile, not shown here, matches closely to that of the force profile, suggesting that high forces and friction is the primary mode of temperature increase. Heating, as a result of attenuation of the ultrasonic wave at these low frequencies and acoustic intensities is less likely.

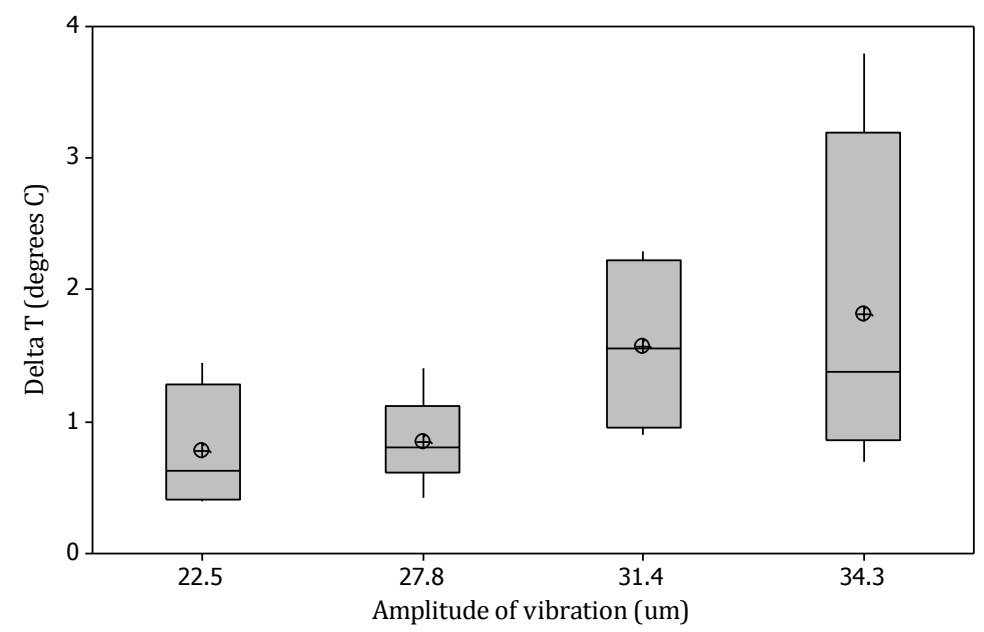

FIGURE 4. $\Delta \mathrm{T}$ for waveguide perforation for a range of amplitudes of vibration.

The results highlight a number of potential benefits and considerations. Firstly, the results show that soft tissue can be perforated with lower forces when compared with non-activated waveguides. This would have to be assessed for useful tip configurations applicable to surgery. Secondly, the risk of perforating tissue accidently may increase with increasing ultrasonic power (amplitudes of vibration). It is also noted that all these tests were conducted at relatively low acoustic intensities $\left(<4 \mathrm{~W} / \mathrm{cm}^{2}\right)$ when compared with some high power applications commonly reported and as a result there was little evidence of harmful tissue heating.

\section{REFERENCES}

[1] "Press Release: 510(k) Clearance for the CROSSER ${ }^{\text {TM }} 14$ Chronic Total Occlusion Recanalization System - A New, Minimally Invasive Option to Bypass Surgery," FlowCardia Inc., Jan. 2007.

[2] R. J. Siegel,

DonMichael,T.A.,Fishbein,M.C.,Bookstein,J.,Adler,L.,Reinsvold,T.,DeCastro,E.,Forrester,J.S., "In Vivo Ultrasound Arterial Recanalization of Atherosclerotic Total Occlusions," Journal of the American College of Cardiology, vol. 15, pp. 352-3., 1990.

[3] G. G. Hartnell, J. M. Saxton, S. E. Friedl et al., "Ultrasonic Thrombus Ablation: In Vitro Assessment of a Novel Device for Intracoronary Use," Journal of Invasive Cardiology, vol. 6, pp. 69-76, 1993.

[4] S. Atar, H. Luo, T. Nagai et al., "Ultrasonic Thrombolysis: Catheter-Delivered and Transcutaneous Applications," European Journal of Ultrasound, vol. 9, no. 1, pp. 39-54, 1999.

[5] M. P. Wylie, G. B. McGuinness, and G. P. Gavin, "Therapeutic ultrasound angioplasty: the risk of arterial perforation. An in vitro study.," Conf Proc IEEE Eng Med Biol Soc, vol. 2009, pp. 282-5, 2009. 